\title{
Crenças de eficácia de professores: validação da escala de Woolfolk e Hoy
}

\author{
José Aloyseo Bzuneck ${ }^{1}$ \\ Sueli Édi Rufini Guimarães²
}

\begin{abstract}
Resumo
Crenças de eficácia do professor referem-se a percepções de poder organizar e implementar cursos de ação exigidos para conseguir resultados acadêmicos. Pesquisas indicam que a eficácia do professor se relaciona com o desempenho. A motivação e o senso de eficácia dos estudantes influencia o nível de aspiração do professor, o esforço aplicado no ensino e o seu comportamento em sala de aula, principalmente quanto ao planejamento e à organização das atividades escolares. Entre diversos instrumentos elaborados para medir o senso de eficácia do professor, a escala de Woolfolk e Hoy contém 20 itens que avaliam dois aspectos distintos, que são: o senso de eficácia pessoal e senso de eficácia do ensino. Este trabalho objetivou levantar as propriedades psicométricas de uma versão da escala para o português, com uma grande amostra brasileira. Resultados da análise fatorial exploratória, correlações entre as subescalas e índices de consistência interna revelaram que o instrumento é adequado para avaliação do senso de eficácia do professor com os dois referidos componentes. A discussão focalizou o significado dos dois fatores relacionados com as subescalas, mostrou as implicações para futuras pesquisas e apresentou sugestões para a criação de instrumentos de medida dessas variáveis.

Palavras-Chave: Crenças de eficácia; Senso de eficácia do professor; Validação de escalas.
\end{abstract}

\section{Teachers' efficacy beliefs: Woolfolk \& Hoy's scale validation}

\begin{abstract}
Teachers' efficacy beliefs relate to the judgement of their capabilities to bring about desired outcomes in classroom. Research evidence has consistently shown that teachers' efficacy relate to students' achievement, motivation, and efficacy beliefs. Moreover, it influences teachers' level of aspiration, effort in teaching, and behavior in classroom regarding tasks planning and organization. Among several instruments created to measure teachers' efficacy beliefs Woolfolk \& Hoy's scale contained 20 Lykert-type items that assess two distinct variables: personal efficacy and teaching efficacy. Present study aimed to assess psychometric proprieties of that scale's translation into portuguese and applied in a large Brazilian sample. Exploratory two-factor analysis, between-scales correlation and internal consistency indexes indicate instrument's validity and reliability. Nevertheless, meaning of these results and implications for future research were discussed, and new paths for advanced studies on efficacy assessment were proposed.
\end{abstract}

Keywords: Teachers' efficacy; Assessment of teachers' efficacy beliefs; Scale validation.

\section{Introdução}

As pesquisas sobre crenças de eficácia têm evidenciado, de modo consistente, as implicações educacionais dos julgamentos feitos pelo professor sobre sua capacidade de exercer ações que influenciem a aprendizagem e o envolvimento de seus alunos. Diferentes que são de autoconceito e de outras formas de autopercepções de capacidade, trata-se aqui de expectativas ou "crenças nas próprias capacidades de organizar e executar cursos de ação necessários para produzir determinados resultados" (Bandura, 1997, p. 3). Outros autores especificam adicionalmente que, quando se trata de professores, os cursos de ação são aqueles "exigidos para realizarem com êxito uma tarefa de ensino, num dado contexto" (Tschannen-Moran, Hoy \& Hoy, 1998, p. 233).

No caso específico das atividades de ensino em escolas, a experiência diária revela que inúmeros obstáculos, reveses, fracassos e frustrações podem abalar a motivação dos professores para persistirem em seu empenho profissional. Em tais condições, tem-se constatado que muitos tendem a abandonar a carreira. Quando não desistem, mantêm apenas uma postura burocrática em seu trabalho, ou se tornam vítimas crônicas de estresse físico e psicológico.

Endereço para correspondência:

${ }^{1}$ Rua Rui Barbosa, 187 - J. Shangri-lá A - Londrina-PR - 86070-610

E-mail: bzuneck@sercomtel.com.br

${ }^{2}$ Rua Rangel Pestana 340, apto. 1.301 - Londrina-PR - 86062-020

E-mail: jsgj@uel.br 
Entretanto, uma quantidade considerável de pesquisas (para uma revisão ver, por exemplo, Bzuneck, 2000; Luppi, 2003) tem revelado que as crenças de autoeficácia fazem diferença para a motivação dos professores e até para seu bem-estar pessoal no trabalho. A título de exemplo, aqueles que desenvolveram sólidas crenças de auto-eficácia revelam, até nas circunstâncias mais adversas, atitudes e comportamentos adaptadores. Assim, apresentam níveis mais elevados de comprometimento com o ensino; adotam procedimentos mais eficazes para lidar com alunos portadores de algum problema na aprendizagem; são mais propensos a introduzir práticas inovadoras; assumem uma postura mais democrática em classe, promotora de autonomia e confiança; e administram eficazmente fatores acadêmicos estressantes mediante estratégias de solução de tais problemas. Semelhantes resultados explicam o crescente apreço entre pesquisadores da área educacional pelo estudo dessa variável motivacional (Graham \& Weiner, 1996), inclusive em nosso meio (Bzuneck, 1996; Fregoneze, 2000; Guimarães, 2003; Luppi, 2003).

\section{Origens das crenças de auto-eficácia}

Diversos fatores contribuem para a ocorrência de um processo de autopersuasão, pelo qual o indivíduo desenvolve as crenças de auto-eficácia. Apoiado em pesquisas, Bandura (1986; 1997) identifica quatro fatores com potencial de influenciar nessas crenças, qualquer que seja a área de aplicação. O primeiro e mais decisivo deles consiste nas experiências reais de êxito em atividades anteriores da mesma natureza. Tal sucesso propicia à pessoa informação convincente de que possui as capacidades necessárias para enfrentar desafios similares. A seguir, uma vez consolidadas as crenças de auto-eficácia, nem mesmo ocasionais fracassos chegam a alterá-las. $O$ segundo fator são experiências vicárias, ou seja, pela observação de modelos que, em situações similares, chegaram a êxito, a pessoa conclui também ser capaz de realizar o mesmo. Outro fator é a comunicação verbal pela qual outras pessoas podem persuadir alguém de que pode dar conta de determinada tarefa. Todavia, Bandura (1997) alerta que tanto a influência vicária como a persuasão verbal somente terão efeito positivo com a condição de que, com as tentativas, a pessoa chegue a ser bem sucedida em seus esforços. Um quarto fator são determinados estados fisiológicos que acompanham certos enfrentamentos. Assim, quando a pessoa se sente altamente ansiosa diante de uma tarefa, tal estado, com seus componentes psicofisiológicos, propicia informação de mais baixa capacidade. Por essa razão, caso a pessoa não supere essa condição emocional negativa, a previsão é de não envolvimento com a atividade, por não acreditar ser capaz de cumpri-la.

Como foi salientado por Tschannen-Moran et al. 1998, comentando Bandura (1997), nenhuma dessas quatro fontes terá influência direta na formação das crenças de auto-eficácia, mas todas elas dependem ainda de um processamento cognitivo de interpretação e avaliação tanto das capacidades como da tarefa em questão. Em outras palavras, é a própria pessoa que, em última instância, pondera suas capacidades de exercer ações pertinentes na contingência de uma determinada tarefa, num certo contexto.

\section{A mensuração das crenças de auto-eficácia}

A primeira tentativa de medir esse constructo em relação a professores de que se tenha notícia apareceu num questionário de pesquisa nos anos 70, conduzida pela $\mathrm{R} A N D$ Corporation entre professores de um determinado distrito educacional norte-americano (Ashton, 1984; 1985; Dembo \& Gibson, 1985). Àquela época, o referencial utilizado foi a teoria da aprendizagem social de Rotter (1966). A medida consistia de dois itens, a serem marcados em uma escala Likert e o resultado de ambas as marcações seria a medida de eficácia do professor. $\mathrm{O}$ item 1, que contemplava influências contextuais sobre a eficácia, vinha com a seguinte redação: "Quando a aprendizagem dos alunos vai mesmo mal, um professor não pode fazer muito porque a maior parte da motivação e desempenho do aluno depende de seu ambiente no lar". E o item 2, centrado exclusivamente na crença pessoal do professor, aparecia neste enunciado: "Se eu realmente me empenhar com afinco, posso dar conta até dos alunos mais difíceis e desmotivados". A concordância do professor com o conteúdo do item 1 denotaria sua crença no poder exercido pelos fatores externos, superando todos os seus esforços para influenciar a motivação e o desempenho de seus alunos. Por essa razão, era considerada mais forte a crença de eficácia quando era maior a discordância com o teor da frase. Já em relação ao segundo item, a anuência do professor expressaria confiança em sua capacidade pessoal de superar os obstáculos concernentes ao desenvolvimento de seus alunos, ou seja, o reforçamento para as atividades de ensino estariam sob seu controle.

Recentemente, Tschannen-Moran \& Hoy (2001), ao assinalarem que o constructo de eficácia do professor é algo "escorregadio", mantêm o pressuposto básico da escala da Rand Corporation, de que tanto fatores externos à sala de aula como fatores intrapessoais do professor devem ser contemplados nas mensurações. Entretanto, surgiu na década de 80 uma mudança de perspectiva nas mensurações, quando os 
autores se voltaram para a Teoria Sociocognitiva de Bandura (Bandura, 1977, 1986, 1997), que introduziu novos conceitos relacionados ao constructo de auto-eficácia.

Ashton e seus colaboradores (cf. Ashton, 1984; 1985) são considerados os primeiros a reportarem-se, em seus estudos, à teoria de Bandura (1977). Numa primeira pesquisa com 48 professores(as) do ensino médio, Ashton, Webb \& Doda (citados em Ashton, 1984) utilizaram os mesmos dois itens dos estudos pioneiros da Rand Corporation, além de entrevistas com seus sujeitos. Numa tentativa de interpretação relacionada com a proposta de Bandura (1977), Ashton e seus colaboradores identificaram o primeiro item do citado teste da Rand Corporation ("...um professor não pode fazer muito...”) como representativo de um constructo que passaram a denominar eficácia do ensino em geral, equivalente ao que Bandura havia denominado como expectativa de resultado. Já o segundo item (“... eu posso dar conta...") é indicador de eficácia pessoal no ensino e corresponderia à expectativa de auto-eficácia de Bandura.

Subseqüentemente, Gibson \& Dembo (1984; ver também Dembo \& Gibson, 1985) elaboraram uma escala Likert com 30 itens para avaliar as crenças de eficácia de professores. Mediante análise fatorial das respostas de uma grande amostra de professores(as) do ensino básico, foram identificados dois fatores denominados de eficácia do ensino e eficácia pessoal, que refletiriam, segundo eles, a distinção original de Bandura (1977), respectivamente, entre expectativas de resultados e expectativas de eficácia.

A distinção entre crença de eficácia pessoal no ensino e crença de eficácia do ensino em geral passou a ser adotada pela maioria dos pesquisadores. Woolfolk e Hoy (1990), porém, apenas argumentam que essas duas dimensões, originadas empiricamente dos estudos de Gibson e Dembo (1984), não correspondem, de um ponto de vista teórico-conceitual, exatamente àquelas propostas originalmente por Bandura (1977).

A partir de então, diversas outras escalas foram construídas e submetidas a procedimentos de análise fatorial, além do índice de consistência interna pelo alfa de Cronbach. Merecem especial menção o instrumento de Woolfolk e Hoy (1990), que se mostra fortemente tributário da proposta anterior de Gibson e Dembo (1984); o de Guskey e Passaro (1994), com inovações de caráter conceitual; o de Goddard, Hoy e Hoy (2000), voltado à mensuração da eficácia coletiva dos professores; a escala de Tschannen-Moran e Hoy (2001), contemplando três fatores que correspondem à eficácia dos professores no uso de estratégias de ensino (fator 1); eficácia no gerenciamento de situações imprevistas (fator 2); e eficácia em conseguir engajamento dos alunos (fator 3); e, por fim, o instrumento recente de
Friedman e Kass (2002), com dois fatores subjacentes: a eficácia do professor no contexto da sala de aula (fator 1) e o grau de seu envolvimento com a escola como um todo (fator 2).

No Brasil, Bzuneck (1996) traduziu e utilizou em pesquisa, com uma grande amostra de professores do ensino fundamental, a escala de Woolfolk e Hoy (1990). O tratamento estatístico dispensado às respostas confirmou a necessidade de se distinguir o senso de eficácia pessoal (o grau em que uma pessoa acredita poder responder às demandas da situação de ensino) e o senso de eficácia do ensino (crença de que os professores, em geral, estão aptos a atender eficazmente os desafios inerentes ao ensino).

O objetivo do presente estudo foi levantar, mediante técnicas de análise fatorial, as propriedades psicométricas da versão brasileira da escala de Woolfolk e Hoy (1990). Esses autores haviam descoberto, por meio de análise fatorial, a presença de dois fatores subjacentes que explicavam $27 \%$ da variância, que conceitualmente foram identificados como crença de eficácia pessoal e crença de eficácia do ensino. Dessa forma, a presente investigação, ao definir a validade de constructo da versão brasileira desse instrumento, espera contribuir para o avanço das pesquisas na área em nosso meio.

\section{Método}

\section{Participantes}

Foram trabalhados os protocolos de respostas de 422 professoras das quatro primeiras séries do Ensino Fundamental do sistema público da região Norte do Paraná. Desse total, 62\% tinham formação em Pedagogia ou outra licenciatura, enquanto os demais apenas tinham curso de Magistério ou ainda freqüentavam curso superior. Distribuíam-se em proporções muito semelhantes pelas três faixas etárias, ou seja, de até 30 anos, entre 31 e 40 e de 41 ou mais. Da mesma forma, eram muito similares em número os grupos formados com base no tempo de magistério, que ia desde menos de seis anos até 21 anos ou mais.

\section{Procedimentos}

Para a realização de seu estudo anterior Bzuneck (1996) contou inicialmente com uma circunstância particularmente favorável, em que todos os professores da rede pública da região passavam, em turmas sucessivas, por um curso de reciclagem obrigatório. Faziam parte desse programa tópicos especiais de Psicologia Educacional, sob responsabilidade do próprio autor. Assim, em cada grupo, logo no início dessa disciplina, ele solicitava a colaboração dos presentes para preencherem o questionário de Woolfolk 
e Hoy (1990), em sua versão brasileira, apresentando-se para tanto justificativas e orientações, além de se salientar o caráter anônimo das respostas. Coletou-se, desta forma, um total de 613 protocolos preenchidos, dos quais, descontadas perdas por razões diversas, 422 $(68,8 \%)$ foram aproveitados para o presente trabalho de validação de constructo.

A fidelidade da versão brasileira do questionário de Woolfolk e Hoy (1990) foi assegurada por dois juízes conhecedores da língua inglesa e ele foi aplicado a um grupo de professores, para se verificar a compreensibilidade dos itens, do que resultou a redação final. $\mathrm{O}$ instrumento consta de 20 itens a serem respondidos numa escala Likert de seis pontos, desde total discordância até inteira concordância. Dos 20 itens, 12 dizem respeito ao constructo eficácia pessoal e oito à eficácia do ensino, uma discriminação comprovada por análise fatorial pelos autores da versão original. A redação final dos 20 itens encontra-se na Tabela 2.

Para a validação do instrumento em português, os procedimentos estatísticos, apoiados no programa computacional Statistica, compreenderam análise fatorial exploratória, com a extração dos componentes principais, correlações entre as médias de cada subescala e o levantamento dos índices de consistência interna de cada subescala, pelo alfa de Cronbach.

\section{Resultados}

A Tabela 1 mostra os resultados da análise fatorial, com extração dos componentes principais que concluiu por seis fatores com valor próprio maior do que 1. Passaram a ser considerados os dois primeiros fatores, de relevância teórica que explicaram 30,86\% da variância dos dados.

Tabela 1 - Fatores obtidos pela análise fatorial, com valor próprio maior do que 1,00, obtidos a partir da Análise dos Componentes Principais, relativamente aos itens da escala de avaliação das crenças de eficácia do professor

\begin{tabular}{cccc}
\hline Fator & Valor próprio & Variância explicada \% & $\begin{array}{c}\text { Variância explicada } \\
\text { acumulada } \%\end{array}$ \\
\hline 1 & 3,51 & 17,55 & 17,55 \\
2 & 2,66 & 13,30 & 30,86 \\
3 & 1,42 & 7,11 & 37,97 \\
4 & 1,25 & 6,29 & 44,27 \\
5 & 1,13 & 5,66 & 49,93 \\
\hline
\end{tabular}

A Tabela 2 apresenta as cargas fatoriais dos itens que se aglutinaram em torno dos dois fatores e que, de acordo com o conteúdo de suas afirmativas, passaram a ser denominados Fator 1, Eficácia Pessoal (EP) e Fator 2, Eficácia do Ensino (EE). Na presente análise, para que um item do questionário pudesse carregar num fator, estabeleceu-se como critério o valor de corte de 0,30. De acordo com Kline (1994), este é um valor aceitável, dado que explicaria pelo menos $9 \%$ da variância total. Todos os itens carregaram acima do critério nos fatores para os quais foram elaborados. No final da Tabela 2 estão indicados o número de itens resultantes para cada fator, a porcentagem de variância explicada pelas duas subescalas, assim como os índices de consistência interna (alfa de Cronbach). Os valores encontrados estão dentro do critério de aceitabilidade para escalas de auto-relato pois, segundo Reeve, Bolt e Yi Cai (1999), devem ser acima de 0,70. 
Tabela 2 - Extração das cargas fatoriais dos itens que compõem a escala de avaliação das crenças de eficácia do professor, com rotação varimax

\begin{tabular}{|c|c|c|c|}
\hline $\begin{array}{l}\mathrm{N}^{o} \text { do } \\
\text { Item }\end{array}$ & Itens & Fator 1 & Fator 2 \\
\hline 1 & Quando realmente tento, sei que posso dar conta dos alunos mais difíceis & 0,48 & \\
\hline 2 & $\begin{array}{l}\text { Se um aluno não se lembra do que eu ensinei numa aula passada, eu saberia como } \\
\text { melhorar sua aprendizagem na lição seguinte }\end{array}$ & 0,38 & \\
\hline 3 & $\begin{array}{l}\text { Quando um aluno consegue uma nota melhor do que usualmente recebe, é porque } \\
\text { eu descobri melhores meios de ensinar aquele aluno }\end{array}$ & 0,58 & \\
\hline 4 & $\begin{array}{l}\text { Se um aluno em minha aula se torna bagunceiro e perturbador, com toda certeza eu } \\
\text { conheço técnicas com as quais eu o controlo rapidamente }\end{array}$ & 0,53 & \\
\hline 7 & $\begin{array}{l}\text { Quando um aluno está tendo dificuldade em alguma tarefa, usualmente sou capaz de } \\
\text { ajustar a tarefa ao nível do aluno }\end{array}$ & 0,55 & \\
\hline 8 & $\begin{array}{l}\text { Quando melhoram as notas de meus alunos, usualmente é porque descobri métodos } \\
\text { mais eficazes de ensino }\end{array}$ & 0,54 & \\
\hline 10 & $\begin{array}{l}\text { Tenho preparo suficiente para lidar com praticamente qualquer problema de } \\
\text { aprendizagem }\end{array}$ & 0,59 & \\
\hline 12 & $\begin{array}{l}\text { Se um aluno chegar a dominar rapidamente um novo conceito, isso pode ser porque } \\
\text { eu conhecia os passos necessários quanto ao ensino daquele conceito }\end{array}$ & 0,51 & \\
\hline 14 & $\begin{array}{l}\text { Quando um aluno se sai melhor do que de costume, normalmente é porque eu estou } \\
\text { me esforçando mais no ensino }\end{array}$ & 0,50 & \\
\hline 16 & $\begin{array}{l}\text { Meu curso de graduação, de preparação para o magistério e/ou experiência deram- } \\
\text { me as habilidades necessária para ser um professor eficaz }\end{array}$ & 0,44 & \\
\hline 17 & $\begin{array}{l}\text { Se eu realmente me empenhar com afinco, posso dar conta até dos alunos mais } \\
\text { difíceis ou desmotivados }\end{array}$ & 0,53 & \\
\hline 19 & $\begin{array}{l}\text { Se algum de meus alunos não puder dar conta de alguma tarefa prescrita, eu seria } \\
\text { capaz de avaliar corretamente se a tal tarefa está ou não no nível adequado de } \\
\text { dificuldade para ele }\end{array}$ & 0,40 & \\
\hline 5 & Se os pais fizessem mais por seus filhos, os professores também poderiam fazer mais & & 0,50 \\
\hline 6 & $\begin{array}{l}\text { Se levarmos em conta todos os fatores, os professores não representam uma } \\
\text { influência poderosa sobre os alunos }\end{array}$ & & 0,47 \\
\hline 9 & $\begin{array}{l}\text { A quantidade do que um dado aluno pode aprender relaciona-se prioritariamente } \\
\text { com sua base familiar }\end{array}$ & & 0,57 \\
\hline 11 & $\begin{array}{l}\text { Um professor tem muitas limitações porque o ambiente de casa do aluno exerce } \\
\text { grande influência sobre o desempenho dele }\end{array}$ & & 0,55 \\
\hline 13 & $\begin{array}{l}\text { Quando a aprendizagem dos alunos vai mal mesmo, a professora não pode fazer } \\
\text { muito, porque a maior parte da motivação e do rendimento de aluno depende de seu } \\
\text { ambiente no lar }\end{array}$ & & 0,67 \\
\hline 15 & $\begin{array}{l}\text { Se os alunos não são disciplinados em casa, provavelmente não aceitarão qualquer } \\
\text { disciplina na escola }\end{array}$ & & 0,56 \\
\hline 18 & $\begin{array}{l}\text { As horas que os alunos passam na classe têm pouca influência sobre eles, em } \\
\text { comparação com a influência de seu ambiente de casa }\end{array}$ & & 0,56 \\
\hline 20 & $\begin{array}{l}\text { Mesmo um professor com boas habilidades de ensino não consegue influenciar } \\
\text { muitos alunos }\end{array}$ & & 0,54 \\
\hline \multicolumn{2}{|c|}{ Número de itens } & 12 & 8 \\
\hline \multirow{2}{*}{\multicolumn{2}{|c|}{$\begin{array}{l}\text { \% da variância } \\
\text { Alfa de Cronbach }\end{array}$}} & 17,55 & 13,30 \\
\hline & & 0,73 & 0,70 \\
\hline
\end{tabular}

Aceitando-se os 12 itens elaborados para a subescala de avaliação da eficácia pessoal e os oito itens originalmente propostos para a subescala de avaliação da eficácia do ensino, foram calculadas as médias obtidas pelos professores. Na subescala de eficácia pessoal a média foi de 4,40 com um desvio padrão de $0,69(\mathrm{~N}=374)$, enquanto na subescala eficácia do ensino a média foi de 3,20 com desvio padrão de 0,89 
( $\mathrm{N}=396)$. O número de participantes variou pelo fato de que alguns deixaram de responder algum item de uma das duas subescalas, sendo então excluídos do cálculo. Por fim, o índice de correlação entre as duas subescalas foi de $-0,14(p=0,006)$, revelador de que os constructos subjacentes a cada subescala são distintos.

\section{Discussão}

Aprimorar os conhecimentos sobre as crenças de eficácia do professor tem implicações educacionais importantes, na medida em que tais crenças revelam-se como um dos determinantes do clima de sala de aula e das metas de realização assinaladas nesse contexto, influenciando a motivação e o desempenho dos alunos. No entanto, o desenvolvimento da pesquisa na área está atrelado à disponibilidade de instrumentos de avaliação consistentes e confiáveis, seja para a realização de estudos exploratórios ou para a verificação da eficácia de trabalhos de intervenção.

As análises realizadas para a validação da versão brasileira da escala de avaliação das Crenças de Eficácia do Professor permitem a conclusão de que ela apresenta propriedades psicométricas adequadas. A estrutura de dois fatores, correspondentes às duas subescalas de avaliação da eficácia pessoal e eficácia de ensino, foi confirmada pelos resultados da análise fatorial exploratória. Nessa análise, os 20 itens da escala total apresentaram cargas fatoriais (mínima 0,38 e máxima $0,67)$ em relação aos fatores para os quais foram elaborados. A correlação próxima a zero encontrada entre as médias nas duas subescalas revelam que estas representam constructos independentes. Os índices de consistência interna (alfa de Cronbach) estão de acordo com os critérios de aceitabilidade.

Os resultados encontrados na presente pesquisa acompanham os de Woolfolk e Hoy (1990), que haviam descoberto estrutura de fatores e índices semelhantes. Segundo os autores, os dois fatores encontrados, medidos pelos itens das escalas denominadas Eficácia Pessoal e Eficácia de Ensino, podem ser interpretados como duas diferentes áreas de atitudes do professor. Vale ressaltar que, subjacente aos itens que compõem a escala de Eficácia do Ensino, está a crença do professor sobre a natureza da capacidade ou, dita em outros termos, da inteligência de seus alunos. Aquele que obtém baixos índices na avaliação de eficácia do ensino acredita que a capacidade é um traço fixo e que a educação é relativamente impotente para interferir nas limitações impostas pela própria constituição da criança ou pelo seu ambiente. Nesse caso, o controle dos alunos, no que se refere ao cumprimento de regras e regulações, parece ser o tipo mais provável de interação ao alcance do professor.
Outra interpretação plausível para a estrutura de dois fatores refere-se às características das afirmativas que compõem as duas escalas. Na avaliação da crença de eficácia de ensino os itens são apresentados em forma de atitudes negativas sobre o ensino, por exemplo, o item 6: "se levarmos em conta todos os fatores, os professores não representam uma influência poderosa sobre os alunos". Nessa avaliação, a não-concordância com a alternativa representaria maiores índices de eficácia. Ao contrário, os itens elaborados para a avaliação da crença na eficácia pessoal são apresentados por meio de atitudes positivas do professor como, por exemplo, o item 10: "tenho preparo suficiente para lidar com praticamente qualquer problema de aprendizagem". Neste caso, maiores índices de eficácia pessoal são revelados pela concordância com os itens apresentados. Questiona-se, então, a possibilidade de que os dois fatores regularmente encontrados nas pesquisas com $\mathrm{O}$ instrumento não estariam apenas retratando essas orientações positivas e negativas das duas subescalas.

Embora reconhecendo a complexidade da estrutura fatorial da escala e a necessidade de mais estudos para o aprofundamento da questão, a versão brasileira da avaliação das Crenças de Eficácia do Professor é um instrumento válido para uso em pesquisas.

\section{Referências}

Ashton, P. (1984). Teacher efficacy: A motivational paradigm for effective teacher education. Journal of Teacher Education, 35, 28-32.

Ashton, P. (1985). Motivation and the teacher's sense of efficacy. Em C. Ames \& R. Ames (Eds.). Research on motivation in education. Vol. 2: The classroom milieu. (p. 141-171). New York: Academic Press.

Bandura, A (1977). Self-efficacy: Toward a unifying theory of behavioral change. Psychological Review, 84(2), 191-215.

Bandura, A (1986). Social foundation of thought \& action A social cognitive theory. Englewood Cliffs: Prentice Hall.

Bandura, A (1997). Self-efficacy. The exercise of control. New York: W. H. Freeman and Company.

Bzuneck, J. A. (1996). Crenças de auto-eficácia de professoras do 1 o grau e sua relação com outras variáveis de predição e de contexto. Arquivos Brasileiros de Psicologia, 48, 57-89.

Bzuneck, J. A. (2000). As crenças de auto-eficácia dos professores. Em F. F. Sisto, G. de Oliveira, \& L. D. T. Fini (Orgs.). (2000). Leituras de psicologia para formaşão de professores. (p. 115-134). Petrópolis, RJ: Vozes.

Psico-USF, v. 8, n. 2, p. 137-143, Jul./Dez. 2003 
Dembo, M. H. \& Gibson, S. (1985). Teachers' sense of efficacy: An important factor in school improvement. The Elementary School Journal, 86, 173-184.

Fregoneze, G. B. (2000). Crenças de auto-eficácia de professores em situação de alterações curriculares no ensino médio. (Dissertação de Mestrado). Londrina: Universidade Estadual de Londrina - Centro de Educação, Comunicação e Artes.

Friedman, I. A. \& Kass, E. (2002). Teacher self-efficacy: A classroom-organization conceptualization. Teacher and Teaching Education, 18, 1-12.

Gibson S. \& Dembo, M. H. (1984). Teacher efficacy: A construct validation. Journal of Educational Psychology, 76, 569-582.

Goddard, R. D., Hoy, W. K. \& Hoy, A. W. (2000). Collective efficacy: Its meaning, measure, and impact on student achievement. American Educational Research Journal, 37, 479-507.

Graham, S. \& Weiner, B. (1996). Theories and principles of motivation. Em D. C. Berliner \& R. C. Calfee (Eds.). Handbook of educational psychology. (p. 6384). New York: Simon \& Schuster Macmillan.

Guimarães, S. E. R. (2003). Avaliação do estilo motivacional do professor: adaptação e validação de um instrumento. (Tese de Doutorado). Campinas: Universidade Estadual de Campinas - Faculdade de Educação.

Guskey, T. R. \& Passaro, P. D. (1994). Teacher efficacy: A study of construct dimensions. American Educational Research Journal, 31, 627-643.
Kline, P. (1994). An easy guide to factor analysis. New York: Routledge.

Luppi, M. A. R. (2003). As crencas de eficácia de professoras do Ensino Fundamental em diferentes contextos escolares. (Dissertação de Mestrado). Londrina: Universidade Estadual de Londrina - Centro de Educação, Comunicação e Artes.

Reeve, J., Bolt, E. \& Yi Cai (1999). Autonomysupportive teachers: How they teach and motivate students. Journal of Educational Psychology, 3, 1-12.

Rotter, J. B. (1966). Generalized expectancies for internal versus external control of reinforcement. Psychological Monographs, 85.

Tschannen-Moran, M. \& Hoy, A. W. (2001). Teacher efficacy: Capturing an elusive construct. Teaching and Teacher Education, 17, 783-805.

Tschannen-Moran, M., Hoy, A. W. \& Hoy, W. K. (1998). Teacher efficacy: Its meaning and measure. Review of Educational Research, 68, 202-248.

Woolfolk, A. E. \& Hoy, W. K. (1990). Prospective teachers' sense of efficacy and beliefs about control. Journal of Educational Psychology, 82, 81-91.

Recebido em maio de 2003 Reformulado em outubro de 2003 Aprovado em dezembro de 2003

Sobre os autores:

José Aloyseo Bzuneck tem mestrado e doutorado em Psicologia do Escolar pelo Instituto de Psicologia da Universidade de São Paulo, é professor na Universidade Estadual de Londrina. No Programa de Pós-Graduação, coordena estudos na linha de Ensino e Motivação.

Sueli Edi Rufini Guimarães é psicóloga, mestre em Educação pela UEL e doutora em Educação pela UNICAMP. É professora de Psicologia na graduação e atua no Programa de Pós-Graduação em Educação na Universidade Estadual de Londrina. 
